\title{
ICAO'S ROLE IN ENVIRONMENTAL PROTECTION AND ITS SHORTCOMINGS UNDER RAPID GROWTH OF AVIATION INDUSTRY
}

\author{
Jean Claude Geofrey Mahoro \\ School of Law, University of Rwanda, Rwanda \\ gmahoro88@gmail.com
}

\begin{abstract}
The growth of the aviation sector has significantly contributed to the global interconnectivity since World War II and presented a strong need for regulation. The Chicago Convention is the first air law that shaped the aviation industry. With that, the United Nations General Assembly set up the International Civil Aviation Organisation (ICAO) with responsibilities that could realise the aviation's ideal. Despite this development, environmental protection was not a serious concern. However, aviation emissions and noise were later documented to be a serious threat to human health and welfare. ICAO, in its remits, has played a significant role in by establishing a regulatory framework through its policies and standards. With doctrinal method, the researcher discusses those policies and standards in the environmental perspective and their shortcomings in the prevention of GHG emissions and aircraft noise. He also reflects the importance of the United Nations Framework Convention on Climate Change (UNFCCC) 1992 and Kyoto Protocol 1997. Considerably, this paper highlights some areas that need improvements such as ICAO policies and standards' implementation mechanisms, Global Market-Based Measure (GMBM), Radio Frequency $(R F)$ spectrum, and conventional framework in ICAO. Hence, the researcher recommends respective stakeholders to enhance their partnership by embracing the concept of sustainability in the aviation industry.
\end{abstract}

Keywords: Aviation; ICAO; Policies and Standards; Environmental Protection; Emissions

\section{Introduction}

Contemporarily, there is a need for action to environmental protection due to its constant changes. Individuals, institutions, and States are concerned, although the latter is the most responsible at the international level. As a specialised agency of the United Nations, International Civil Aviation Organisation (ICAO) through its policies and standards has attempted to develop an environmental protection framework in the aviation industry. This is associated with the global environmental protection system that began in 1972 with the Stockholm Conference and its antecedent, the International Plant Protection Convention (IPPC) in 1951. The Stockholm conference has become the first of other multilateral treaties regarding the environmental protection including the United Nations Framework Convention on Climate Change (UNFCCC) 1992, Kyoto Protocol 1997 and the Paris Agreement on climate change 2015. Despite the significant role of those treaties that showed the cooperation of the international community of states, environmental protection has become a thematic issue that needs serious attention. The 1987 Bratland Report brought another important concept of sustainable development with which all economic activities, including the aviation sector, should 
embrace to secure a better world for present and future generations. With this concept, the 2000 MDGs and Post-2015 SDGs' agenda have incorporated environmental protection.

The technological advancement has taken the aviation sector farther, but it was associated with emissions and aircraft noise that posed a threat to the environment in different settings. The rise of greenhouse gases emissions has contributed to climate change and global warming. Besides, aircraft noise is another emerging environmental pollution harmful to human health. For that reason, environmental protection needs to be taken further in various areas underpinning human health. So, the state of the art of this paper is focus on the regulatory framework of the International Civil Aviation Organisation (ICAO) in environmental perspective as the aviation industrial advancement has raised an inquiry about what will be next to the current environmental challenges.

\section{Methods}

The present research method is doctrinal, under which the primary legal materials and secondary legal materials play a critical role. The researcher has used primary legal materials such as UN conventions, conventions, resolutions, protocols, declarations, and case laws (where available) to assess whether the ICAO policies and practices comply with their provisions. Besides, he has employed secondary legal materials, including books, journals, legal directories, treatises, and useful online-based publications to scrutinise the applicability of norms and principles provided under international law. This diversity of knowledge from scholars has helped the researcher to reach a reliable conclusion and recommendations contributing to the aviation sector and environment in the context of international law.

\section{Results and Discussion}

The following discussion takes a reader to the development of the aviation industry since the establishment of the Chicago Convention and the ICAO. It looks into States' obligations towards the environment in the aviation sector resulting from the United Nations Framework Convention on Climate Change (UNFCCC) and the Kyoto Protocol. The researcher assesses the role of ICAO in the sector through its policies and standards and marks its shortcomings. He focuses on GHG emissions and aircraft noise as the emerging environmental issues in the aviation sector. Among others, the study identifies the great work of ICAO in the development of the aviation sector, ensuring safety. However, it has also found the ICAO policies' 
implementation mechanisms weak and prone to massive violations by its Member States. Besides, ICAO activities on Global Market-Based Measure (GMBM) do not give hope in slowing down the growth of international aviation greenhouse gases emissions. Then, the researcher recommends an establishment of convention framework to improve the ICAO Members' partnership.

The year 1944 marked a significant advance in the aviation industry as it extended its concern from national to international level. Thus, this advance raised the most significant activities that interconnected the entire globe. Consequently, there was a need for accuracy and safety for the sector to prosper and attain its objectives, which led to the Chicago Convention and the establishment of the ICAO. Despite the advance, the new aviation sector system of the time did not foresee its impacts on the environment in a legal context. However, it indirectly conferred the power of regulating the sector to the ICAO through Article 44 of the Chicago Convention. ${ }^{1}$

The aviation industry has presented a global impact on climate change, water, and air quality, which requires a critical regulatory system at the global level. ${ }^{2}$ The greenhouse gas (GHG) emissions and noise from aircraft have been identified among the threats to human health and welfare. Both problems presented a need for a regulatory system in order to ensure their reduction. It appeals to an inquiry of whether there are specific responsibilities of the aviation sector with regard to environmental protection, and if so, on whom it is pressed? This might be understandable; the Chicago Convention confers a range of responsibilities to the ICAO under which it can develop a regulatory framework in the prevention and reduction of aircraft emissions and noise. Still, is the aviation advancement consistent with environmental sustainability? Considerably, the following discussion addresses those issues.

Following international aviation growth during World War II, there was a need for system regulating international flights, covering technical, economic, and legal issues. In this regard, ICAO is the United Nations specialised agency established on April 4, 1947, following the International Civil Aviation Conference in Chicago after of World War II. ${ }^{3}$ The Chicago conference framed the constitution of the ICAO or the Convention on International Civil Aviation, also known as the Chicago Convention. ICAO came into being after 26 ratifications of

1 Helmut Volger, "ICAO - International Civil Aviation Organization," in A Concise Encyclopedia of the United Nations, (2010), 355-56, https://doi.org/10.1163/ej.9789004180048.i-962.293.

2 FAA Office of Environment and Energy, Aviation Emissions, Impacts \& Mitigation: A Primer, (2015), 1. https://www.faa.gov/regulations_policies/policy_guidance/envir_policy/media/primer_jan2015.pdf.

3 Volger, "ICAO - International Civil Aviation Organization." 
this Convention. ${ }^{4}$ The ICAO headquarter is based in Montreal, Canada. With a vision of achieving the sustainable growth of the global civil aviation system, ICAO develops policies, standards, and recommended practices (SARPs) in the civil aviation sector. In order to reach them, it works with 192 member states and big industry groups. ${ }^{5}$ In this light, ICAO works in cooperation with other UN specialised agencies, including the World Meteorological Organisation (WMO), International Telecommunication Union (ITU), World Health Organisation, to mention but a few. In a matter of environmental protection, ICAO has a Council's Committee on Aviation Environmental Protection (CAEP), which is a channel of its policies and standards.

\subsection{The ICAO Role on Environment Protection}

Concerning environmental protection, ICAO has diverse obligations from multiple conventions related to environmental protection. Although the Chicago Convention does not explicitly address the environmental protection in its entirety due to its drafting purpose, it grants that responsibility to ICAO in the scope of establishing provision. ${ }^{6}$ Article 44 of the Chicago Convention confers responsibilities on ICAO, including the development of principles and techniques of international air navigation. In this context, ICAO should respond to environmental issues in the aviation sector. In addition, the Kyoto Protocol also poses responsibilities to ICAO. Under its Article 2, ICAO should pursue limitation or reduction of GHG emissions not controlled by the Montreal Protocol from aviation bunker fuels working through the ICAO. ${ }^{7}$

Improving the environmental performance of aviation is a challenge ICAO takes very seriously. In fulfilling its responsibilities, the Organization developed a range of standards, policies and guidance material for the application of integrated measures to address aircraft noise and emissions embracing technological improvements, operating procedures, proper organization of air traffic, appropriate airport and land-use planning, and the use of market-based options. ${ }^{8}$

\footnotetext{
4 "The International Civil Aviation Organization (ICAO)," Worldmark Encyclopedia of Nations (Encyclopedia.com, 2019), https://www.encyclopedia.com/history/encyclopedias-almanacs-transcripts-andmaps/international-civil-aviation-organization-icao.

5 International Civil Aviation Organisation (ICAO), “About ICAO,” www.icao.int, n.d.

6 Secretary-General of the International Civil Aviation Organization, Convention on International Civil Aviation, ed. ICAO, 9 Ed. (Chicago: Authority of Secretary-General of the International Civil Aviation Organization, 2006), 50, https://www.icao.int/publications/Documents/7300_9ed.pdf.

7 Article 2 (2) of the Kyoto Protocol to the United Nations Framework Convention on Climate Change (UNFCCC), 1998.

8 ICAO, 'Environmental Protection', icao.int, Accessed December 3, 2018, https://icao.int/environmentalprotection/Pages/default.aspx.
} 
It is evident that ICAO has responsibilities with regard to the environment in the civil aviation sector. In that sector, ICAO has developed a series of legal instruments in order to reduce aircraft noise and emissions. As a result, its great work has contributed to efficiency in the sector since the 1970s.

In its environmental responsibility, ICAO developed three major environmental goals in 2004 including (1) limiting or reducing the number of people affected by significant aircraft noise; (2) limiting or reducing the impact of aviation emissions on local air quality; and (3) limiting or reducing the impact of aviation greenhouse gas emissions (GHG) on the global climate. ${ }^{9}$ In addition, in order to reduce the impact of civil aviation on the environment, the ICAO Council's Committee on Aviation Environmental Protection (CAEP) adopted strategic objectives that take environmental protection into priority. The CAEP is composed of members and observers from States, intergovernmental and NGOs representing the aviation industry and environmental interests. It is an environmental engine, which undertakes environmental issues at the most concern. The council has to revise and update the policies and practices relating to the environment every three years and submit them to the ICAO Assembly for adoption. Most currently, the Assembly adopted Resolutions A39-1, ${ }^{10}$ A39-2, ${ }^{11}$ and A39-3 ${ }^{12}$ by $2016 .{ }^{13}$

According to the ICAO Business Plan 2017-2019, the aviation sector will be environmentally friendly in two situations; improving the environmental performance of aviation and reducing the environmental impact on global climate. In the first situation, the ICAO will enhance the capabilities of states to apply the integrated measures to address aircraft noise and engine emissions. ${ }^{14}$ In this regards, it will embrace the technological and operational progress, and the use of sustainable aviation alternative fuels and a global market-based measure for international aviation where appropriate. ${ }^{15}$ In the second situation, the ICAO will enhance the capabilities of states to prepare and implement measures in light of reducing the $\mathrm{CO}_{2}$ emissions

9 ICAO, Op. Cit.

10 ICAO, "Resolution A39-1: Consolidated Statement of Continuing ICAO Policies and Practices Related to Environmental Protection - General Provisions, Noise and Local Air Quality" (2016), https://www.icao.int/Meetings/a39/Documents/Resolutions/a39_res_prov_en.pdf.

11 ICAO, "Resolution A39-2: Consolidated Statement of Continuing ICAO Policies and Practices Related to Environmental Protection - Climate Change" (2016), https://www.icao.int/environmentalprotection/Documents/Resolution_A39_2.pdf.

12 ICAO, "A39-3: Consolidated Statement of Continuing ICAO Policies and Practices Related to Environmental Protection - Global Market-Based Measure (MBM) Scheme" (2016).

13 ICAO, 'Environmental Protection,' Op. Cit.

14 ICAO, Icao Business Plan $2017 \quad-\quad 2019, \quad(2016), 12, \quad 15, \quad 27, \quad$ and 40, https://www.icao.int/Meetings/a39/Documents/Business Plan 2017-2019.pdf.

15 Ibid. 
from international aviation. It should be under the harmonised global regulatory framework consistent with the UN system environmental protection policies and practices. ${ }^{16}$

One of the key priorities of the ICAO 2020-2022 Business Plan is to enhance the international legal framework as one of the 15 core objectives. To improve the environmental performance of aviation and reduce the environmental impact on global climate have been brought back. ${ }^{17}$ This is to show the significance of environmental protection. However, 20162020 Business Plan marked a slow pace in implementation of the Environment $\mathrm{CO}_{2}$ Reduction State Action Plans and the Carbon Offsetting and Reduction Scheme for International Aviation (CORSIA). ${ }^{18}$ All the framework can only be achieved upon the international cooperation of States and under robust mechanism for implementation of ICAO policies and standards.

\subsection{Emissions and Noise}

The environmental pollution in the aviation industry has two viewpoints, the emissions and noise. The two issues are threats to human health and welfare. Emissions contribute to the global warming that subsequently changes the Earth's climate. Whereas, the noise of an aircraft from its take-off and landing or flight at low altitude is another pollution which strongly affects people located nearby the airports and other areas in that might be affected.

\subsubsection{Emissions}

The aviation industry development has contributed significantly to human needs. It permitted global integration, which was problematic. In contrast, the aircrafts' emissions pose threats to human health and welfare. ${ }^{19}$ In the present work, emissions refer to the greenhouse gases (GHG) discharged into the air by international aviation. According to Live Science, a greenhouse gas is defined as 'any gaseous compound in the atmosphere that is capable of absorbing infrared radiation, thereby trapping and holding heat in the atmosphere. ${ }^{, 2}$ From this definition, it is clear that aviation activities contribute a lot to the GHG emissions.

16 Ibid.

17 ICAO, "ICAO Business Plan 2020 - 2022 Sixteenth Meeting of Civil Aviation Authorities," in Sixteenth Meeting of Civil Aviation Authorities (Lima, Peru: ICAO, 2018), 4-5, https://www.icao.int/SAM/Documents/2018-RAAC16/SAM Business Plan for 2018 DGCA.pdf.

18 Ibid., p. 22.

19 Prof. (Dr.) Ranbir Singh, Prof. Sanat Kaul, And Prof. (Dr.) Srikrishna Deva Rao, Current Developments In Air And Space Law', Delhi Prof. (Dr.) Ranbir Singh (Delhi: Nlud Press, 2012), Papers://Ae99785b-2213-416dAa7e-3a12880cc9b9/Paper/P15001.

20 Marc Lallanilla, "Greenhouse Gas Emissions: Causes \& Sources," livescience, (2019), https://www.livescience.com/37821-greenhouse-gases.html. 
GHG is one of the root causes of global warming, which has become a global concern. According to the Environmental Protection Agency (EPA), the most significant greenhouse gases include water vapour $\left(\mathrm{H}_{2} \mathrm{O}\right)$, carbon dioxide $\left(\mathrm{CO}_{2}\right)$, methane $\left(\mathrm{CH}_{4}\right)$ and nitrous oxide $\left(\mathrm{N}_{2} \mathrm{O}\right){ }^{21}$ Among others, the most dangerous is $\mathrm{CO}_{2}$, which increased tremendously since the industrial revolution. According to the National Oceanic and Atmospheric Administration (NOAA), the $\mathrm{CO}_{2}$ increased to 100 times faster than it did at the end of the last ice age. In addition, the Fluorinated gases, considered greenhouse gases, also created by the industrial processes and, however few in concentration, have been classified as high "global-warming potential" (GWP) gases due to their effective trap of heat. ${ }^{22}$

According to ICAO, the aircraft engine produces emissions similar to those emissions resulting from fossil fuel combustion. ${ }^{23}$ Aircraft emissions include carbon dioxide $\left(\mathrm{CO}_{2}\right)$, water vapour, hydrocarbons, carbon monoxide, nitrogen oxides, sulfoxides, and black carbon. ${ }^{24}$ Although the effects of emissions from aircraft to the atmosphere are different, the most dangerous are those of $\mathrm{CO}_{2}$. According to NASA, the $\mathrm{CO}_{2}$ level has increased by 38 percent since the industrial revolution period to 2009. Consequently, the year 2014 has become the hottest year on record comparing the previous 15 years. ${ }^{25}$ Under the following excerpt, the Center for Biological Diversityclarifies the danger of aircraft emissions to climate change.

... aircraft emit gases and particles which alter the atmospheric concentration of greenhouse gases, trigger the formation of condensation trails and may increase cirrus cloudiness, all of which contribute to climate change ... aircraft are estimated to contribute about 3.5 per cent of the total radiative forcing (a measure of change in climate) by all human activities and that this percentage, which excludes the effects of possible changes in cirrus clouds, was projected to grow. ${ }^{26}$

The Report from Intergovernmental Panel on Climate Change (IPCC) and the Scientific Assessment Panel to the Montreal Protocol on Substances that Deplete the Ozone Layer has recognised the effects of some aircrafts' emissions, excluded others' effects and presented

21 Ibid.

22 Lallanilla, Op. Cit.

23 ICAO, “Airplane Emissions," Center for Biological Diversity (International Civil Aviation Organisation),

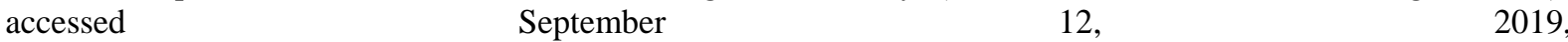
https://www.biologicaldiversity.org/programs/climate_law_institute/transportation_and_global_warming/airplan e_emissions/.

24 Ibid.

25 Steve Cole, "2014 Warmest Year in Modern Record," Global Climate Change, (2015), https://www.nasa.gov/press/2015/january/nasa-determines-2014-warmest-year-in-modern-record.

26 ICAO, Loc. Cit. 
uncertainty on the rest. ${ }^{27}$ In this light, the ICAO Assembly in 2001 argued States to develop scientific research in order to work out these uncertainties, which would limit the ability to project aviation impacts on climate and ozone. ${ }^{28}$ According to the Fourth Assessment Report (IPCC AR4) which followed in 2007, the climate effects of contrails have decreased and estimated at $3 \%$ of the total of the anthropogenic radiative forcing by all human activities; the $\mathrm{CO}_{2}$ aviation emissions was approximated to $2 \%$ of the global GHG emissions. ${ }^{29}$ The report also suggested that the improved fuel efficiency could contribute to the medium-term mitigation for $\mathrm{CO}_{2}$ emissions from the aviation sector, and lastly, those improvements were only expected to partially offset the growth of $\mathrm{CO} 2$ aviation emissions. ${ }^{30}$

Annexe 16 to the Chicago Convention regarding environmental protection (vol. II) addresses the aircraft emissions through ensuring the air quality near the airports. Under this Volume, the ICAO imposes the obligations to its members to limit emissions of oxides of nitrogen (NOx), carbon monoxide, unburned hydrocarbons, for a reference landing and take-off (LTO) cycle below 915 meters of altitude $(3,000 \mathrm{ft})$. The annexe 16 has been updated recently in 2016 and incorporated the emissions compliance demonstration reporting system that entails the required technical information in environmental respect. ${ }^{31}$

Apart from the ICAO, under the adjoint approach to the global chemical transport model (GEOS-Chem), there is a project that aims at reducing aviation emission impacts ensuring the air quality. ${ }^{32}$ The National Aerospace Standards (NAS) and Global Rapid Aviation Air Quality are projects designated to mitigate the air quality impacts of aviation through the development of tools that can rapidly assess the air quality impacts of aviation emissions. ${ }^{33}$ Those projects aimat allowing the identification of the best mitigation paths. The area of concern is pressed on both $\mathrm{PM}_{2.5}$ and ozone-related impacts from aviation emissions. ${ }^{34}$

Aviation emissions were remarked to have a big impact on global warming and climate change, which is a threat to human health and welfare. In order to address this problem, the ICAO has done some work through the development of policies and standards. However, the

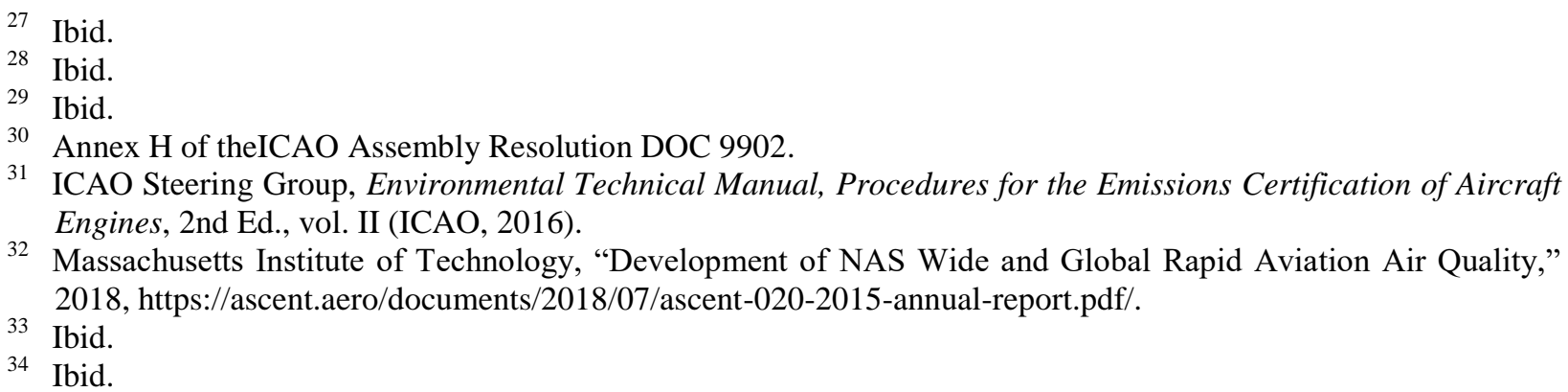


ICAO Council has been unable to adjudicate the environmental issues in the aviation sector. This is associated with two reasons. First, as the bilateral agreements in the aviation sector increased in the globalisation era, State Parties chose to refer their disputes to arbitration mechanisms. Second, Contracting Parties abandoned the Council because since its establishment it never decided on the merits particularly in environmental respect, which marks its inability. ${ }^{35}$

The ICAO Council has been an adjudicating forum on the interpretation and violation of the Chicago Convention. Under Article 66 of the Chicago Convention, the Council also serves a role of settling disputes pertaining to the International Air Services Transit Agreement and the International Air Transport Agreement. ${ }^{36}$ Under a bilateral agreement, contracting parties may designate the ICAO Council as their dispute settlement body ina matter of interpretation and application of the Convention. ${ }^{37}$ In that case, any contracting party can request the Council to investigate the situations that tend to jeopardise the development of international air navigation. However, the ICAO Council never issued a decision on the merits, which makes it debatable that it has been unable to exercise its power under Chapter XVIII of the Convention. ${ }^{38}$

Moreover, amidst the five cases held by the ICAO Council under Article 84 of the Chicago Convention, it is only the 2000 'hush-kit case' that was about environmental protection. It was between the EU Member States and the United States. This case was about the application of the EU Directive known as the 'hush-kit regulation' to reduce the aircraft noise-related problems. ${ }^{39}$ The implementation of this regulation would deny the US carriers to fly their older aircrafts to the EU. Consequently, the case was filed to the ICAO Council and later settled by the Council's President who acted as the Conciliator and reached the final step whereby the EU repealed the regulation with another Directive satisfactorily to both Parties. ${ }^{40}$

\subsubsection{Aviation Noise}

The community around the airports have become annoyed by the aircraft's' noise in their ascending and descending. The aircraft noise has an impact on the mental and physical health of

\footnotetext{
35 Mathieu Vaugeois, "Settlement of Disputes at ICAO and Sustainable Development," no. 4 (2016): 4-6, https://www.mcgill.ca/iasl/files/iasl/occasional_paper_iv_settlement_of_disputes.pdf.

36 Vaugeois, Op. Cit.

37 ICAO, Chapter XVIII of the Chicago Convention, 9th ed. (International Civil Aviation Organization, 2006), http://www.icao.int/publications/Pages/doc7300.aspx.

38 Vaugeois, "Settlement of Disputes at ICAO and Sustainable Development."

39 Guy Visel, "EU-U.S. Hush-Kit Battle Ends in 'Balanced Approach' Pact," AINonline, 2008, https://www.ainonline.com/aviation-news/aviation-international-news/2008-05-06/eu-us-hush-kit-battle-endsbalanced-approach-pact.

40 Vaugeois, Loc. Cit.
} 
people who live below the flight trails of commercial and private aircraft, especially around the airports. According to Professor Dr. Paul Stephen Dempsey, the aircraft noise was linked to stress, hypertension, sleep disturbances, work-related performance, learning, and academic performance since the last five decades. ${ }^{41}$ According to Prof. (Dr.) Ranbir Singh et al., the airports' noise and the noise from overflying at low altitudes led to local protest, which resulted in night curfews at many airports under unilateral decisions of municipalities. ${ }^{42}$ Those restrictions were found to have a significant impact on international air transport and invite the ICAO to intervene and come up with another global harmonised solution. ${ }^{43}$

In 2001, the ICAO General Assembly adopted a 'balanced approach' to environmental harm, attempting to 'achieve a balance between the benefit accruing to the world community through civil aviation and the harm caused to the environment in certain areas through the progressive advancement of civil aviation.' Each airport identifies a noise problem based on objective data, considers all available alternatives for addressing the noise issue, and selects the most cost-effective approach. ${ }^{44}$

As highlighted in the above passage, in order to reduce the aviation noise potential harm to the people, the ICAO General Assembly, through the annex 16 to the Chicago Convention regarding environmental protection (vol. I) addresses aircraft noise through 'balanced approach. ${ }^{45}$ The balanced approach refers to the assessment of noise problem on certain airports and looking for the most cost-effective measures among the possible measures classified into four principal approaches. ${ }^{46}$ The four approaches include: a) Reduction of noise at source (quieter aircraft); b) Land-use planning and management; c) Noise abatement operational procedures; d) Operating restrictions.

The ICAO has conducted a technical work that counted three years (2013-2016), on its standards, guidance, and policies associated with reducing aircraft noise. Among others, this work investigated a subsonic aircraft, and technology of helicopter noise reduction. Moreover, ICAO has worked on airport land-use planning and airport community engagement in

${ }^{41}$ Professor Dr. Paul Stephen Dempsey, "Environmental Law and Sustainability in International Aviation,” McGill University, (2015), 7, https://doi.org/10.2800/52418.

42 Prof. (Dr.) Ranbir Singh, Prof. Sanat Kaul, Op. Cit.

43 Ibid.

44 Dempsey, "Environmental Law and Sustainability in International Aviation", 8.

45 Transmittal Note, "ANNEX 16 - ENVIRONMENTAL PROTECTION Volume I - Aircraft Noise," Environmental Protection, 2003.

46 ICAO, "Aircraft Noise," www.icao.int, accessed September 12, 2019, https://www.icao.int/environmentalprotection/Pages/noise.aspx. 
environmental management. ${ }^{47}$ The one can criticise the results of those works since the efforts to reduce the noise radiation is still slow. Despite the balanced approach and technical work of ICAO, the noise continued to become a big issue as the aviation sector is growing tremendously, and a number of people experiencing the aircraft noise-related problems took rise. ${ }^{48}$

\subsection{Shortcomings of ICAO and Legal Implications}

The ICAO has not yet set a strategic plan for aviation emission for the long term. In contrast, the International Air Transport Association (IATA) aims at aviation emission reduction towards 2050, which is better than the ICAO aspirational goal to stabilise aircraft emissions at the 2020 levels. ${ }^{49}$ ICAO activities on the Global Market-Based Measure (GMBM), which is expected to address the growth of international aviation emissions has kept slow.

Being an issue beyond the sovereign airspace, the environmental instruments developed by ICAO are not effectively enforceable, they remain soft laws encountering massive violations of most developed countries. There is a need for strong mechanism of enforcement, which presses liabilities on the States in case of violation of international law in this respect. Thus, in order to ensure global environmental protection in the aviation sector, the international community needs to intensify collective proactive efforts for the effective implementation of the ICAO policies and standards.

Aviation uses enormous Radio Spectrum (RF) resources in various activities such as radio communications with aircraft earth stations. In contrast, its activities jeopardise this natural resource, which is scarce and prone to many interferences. The ICAO has not developed its policies and standards while it would be among the most concern of the environmental issues.

In light of emissions from the national and international aviation, there are challenges because of the IPCC and UNFCCC only press responsibilities to nations as those emissions that are calculated as part of national greenhouse gas inventories of Parties. However, the guidelines to both the IPCC and UNFCCC provide an exclusion of emissions of international aviation from national totals for separate reporting purpose. Such an exclusion makes these emissions nonsubjects to limitation and reduction assigned to State Parties under the UNFCCC and Kyoto

47 Ibid.

48 Prof. Umberto Iemma, “Aircraft Noise: An Emerging Environmental Issue,” ANIMA, (2018), https://animaproject.eu/2018/09/aircraft-noise-an-emerging-environmental-issue/.

49 Public Health and Food Safety Committee on the Environment, "Mission Report to the $10^{\text {th }}$ Session of the Committee on Aviation Environmental Protection (CAEP10) of the International Civil Aviation Organisation (ICAO)," 2016. 
Protocol. ${ }^{50}$ In this regard, as a source of scientific information and technical guidance for State Parties to the UNFCCC, Kyoto Protocol, and Paris Agreement, the IPCC, in its assessment on climate change, needs to cooperate with aviation industrial companies and bodies in different countries in order to handle the problem of higher emissions from aircrafts adequately. The following is an example of Indonesia's strategic cooperation.

In the implementation of the United Nations Framework Convention on Climate Change (UNFCCC) of 1992, Indonesia has issued the Presidential Decree No. 61/2011 concerning National Action Plan on GHG Emission Reduction in 2011. Under this Decree, businesses, including the aviation sector, have been given a target of reducing GHG by 26\% upon 2020, which is the pledged target of the Republic of Indonesia. ${ }^{51}$ In this light, Presidential Order No. $71 / 2011$ on the implementation of national GHG inventory in Indonesia mandates various governmental and corporate entities to produce GHG inventories annually. ${ }^{52}$ Besides, the Ministry of Environment coordinates and submits the national inventory to the UNFCCC. Preparing inventories at all levels helps the government to measure the effectiveness of the mitigation actions basing on the collected information. Besides, Indonesia cooperates with neighbouring countries and international organisations in addressing the problem of climate change. Various companies in the air transportation sector including Garuda Indonesia, Sriwijaya Air, Lion Air, and airport operators such as PT Angkasa Pura I and PT Angkasa Pura II as well as government entity Badan Penanggulangan Bencana National (BPBN)/ The National Agency for Disaster Countermeasure embarked on dealing with climate change. ${ }^{53}$

Furthermore, aircraft noise has been another problem of which ICAO has not addressed adequately. It keeps posing a threat to the lives of people living in the vicinity of airports. ${ }^{54}$ This problem presents a need for initiating and funding projects that bring innovative solutions to the problem. For example, the EU under has invested in various scientific and technological research

50 "Emissions from Fuels Used for International Aviation and Maritime Transport," United Nations Climate Change, Accessed September 12, 2019, https://unfccc.int/topics/mitigation/workstreams/emissions-frominternational-transport-bunker-fuels.

51 Michal Nachmany et al., The GLOBE Climate Legislation Study: A Review of Climate Change Legislation in 66 Countries, $4^{\text {th }}$ ed. (London: GLOBE International and the Grantham Research Institute, London School of Economics, 2014), 263-66, http://www.lse.ac.uk/GranthamInstitute/wp-content/uploads/2014/03/Globe2014.pdf.

52 Ibid.

53 Gunawan Djajaputra, Hari Purwadi, and H K Martono Shllm, "Indonesian Civil Aviation Act of 2009 : Aviation Safety , Security and Climate Change," International Journal of Business and Management Invention5, no. 11 (2017): 4.

54 Sofie Iversen, “Aircraft Noise Is Harmful to You,” 2018, https://soundear.com/2018/02/22/aircraft-noiseharmful/. 
projects $^{55}$ aiming at reducing the aircraft noise radiation and alleviating its nuisance to the communities living in proximity of airports. ${ }^{56}$ In addition, the ICAO needs to establish a comprehensive mutual approach reducing aircraft noise instead of restrictions under various cities' regulations that have a potential impact on the development of international aviation.

For the aviation industry to meet the current demands without jeopardising the future generation, the Intergovernmental Panel on Climate Change (IPCC) would also look for technological innovations that could contribute to the reduction of emission. Thus, the potential harm of technological advancement would be balanced with its benefits in the long term, which invokes the concept of sustainability in the aviation sector. Besides, the ICAO mechanisms are more centre and require a strong partnership with the Member States for effective implementation of ICAO policies and standards in their respective territories. Thus, ICAO needs a conventional approach leading to the global sustainable development agenda and reaching globally-harmonised solutions. Its policies and standards would embrace environmental concepts and principles of international law.

\section{Conclusion}

The research at hand has identified a number of impacts of the aviation industry on the environment in different perspectives. The incredible growth of this sector has led to many issues related to direct GHG emissions and aircraft noise. Those problems were associated with different impacts that pose threats to human health and welfare. Among others, global warming and climate change were documented on several occasions. In order to address this thematic issue, ICAO has done great work to ensure environmental protection within the aviation sector. It has contributed to international aviation development through the establishment of policies and standards that give hope to the global community. However, despite the sector's advancements, some areas need special consideration such as implementation mechanisms of the ICAO policies and standards; Global Market-Based Measure (GMBM); effective use of RF spectrum; and development of ICAO Convention framework to enhance the global partnership of States. This initiative will allow the aviation sector to achieve sustainable development embracing environmental protection.

\footnotetext{
55 Horizon 2020 research and innovation programme funds three complementary projects including Aviation Noise Impact Management through Novel Approaches (ANIMA); Aircraft noise Reduction Technologies and related Environmental Impact (ARTEM); and Advanced Aircraft-Noise-Alleviation devices using metamaterials (AERIALIST).

56 Iemma, Op. Cit.
} 


\section{Acknowledgement}

This research did not receive any specific grant from funding agencies in the public, commercial, or non-profit sectors.

\section{References}

Cole, S. "2014 warmest year in modern record."Global Climate Change. Last modified 2015. https://www.nasa.gov/press/2015/january/nasa-determines-2014-warmest-year-in-modernrecord

Committee on the Environment, P. H. and F. S.Mission report to the 10th session of the Committee on Aviation Environmental Protection (CAEP10) of the International Civil Aviation Organisation (ICAO). 2016.

Dempsey, P. D. P. S. "Environmental Law and Sustainability in International Aviation."McGill University, 7 (2015). https://doi.org/10.2800/52418

Djajaputra, D. G., Purwadi, D. H., \& Shllm, P. H. K. M. (2017). "Indonesian Civil Aviation Act of 2009: Aviation Safety , Security and Climate Change." International Journal of Business and Management Invention5, No. 11 (2017): 4.

"Emissions from fuels used for international aviation and maritime transport."United Nations $\begin{array}{lllll}\text { Climate } & \text { Change. } & \text { Accessed } & \end{array}$ https://unfccc.int/topics/mitigation/workstreams/emissions-from-international-transportbunker-fuels

FAA Office of Environment and Energy."Aviation Emissions, Impacts \& Mitigation: A Primer."Last modified

https://www.faa.gov/regulations_policies/policy_guidance/envir_policy/media/primer_jan2 015.pdf

ICAO. "A39-3: Consolidated statement of continuing ICAO policies and practices related to environmental protection - Global Market-based Measure (MBM) scheme."Last modified 2016.

ICAO. "Aircraft Noise."Accessed September 12, 2019. www.icao.int website: https://www.icao.int/environmental-protection/Pages/noise.aspx

ICAO. "Airplane Emissions."Center for Biological Diversity. Accessed September 12, 2019. https://www.biologicaldiversity.org/programs/climate_law_institute/transportation_and_gl obal_warming/airplane_emissions/ 
ICAO."Chapter XVIII of the Chicago Convention ( $9^{\text {th }}$ ed.)." Last modified 2006. http://www.icao.int/publications/Pages/doc7300.aspx

ICAO."ICAO business plan $2017 \quad$ - 2019." 2016. https://www.icao.int/Meetings/a39/Documents/Business Plan 2017-2019.pdf

ICAO. "ICAO business plan 2017 - 2019 (1st Ed.)." Last modified 2016.

ICAO. "ICAO Business Plan 2020 - 2022 Sixteenth Meeting of Civil Aviation Authorities."Sixteenth Meeting of Civil Aviation Authorities, 4-5. Last modified 2018. https://www.icao.int/SAM/Documents/2018-RAAC16/SAM Business Plan for 2018 DGCA.pdf

ICAO. "Resolution A39-1: Consolidated statement of continuing ICAO policies and practices related to environmental protection - General provisions, noise and local air quality." Last modified 2016.

ICAO. "Resolution A39-2: Consolidated statement of continuing ICAO policies and practices related to environmental protection - Climate change." Last modified 2016.

ICAO Steering Group."Environmental Technical Manual, Procedures for the Emissions Certification of Aircraft Engines (2nd Ed.)."ICAO. Last modified 2016.

Iemma, P. U. (2018). "Aircraft noise: an emerging environmental issue."ANIMA. Last modified 2018. Accessed September 12, 2019. https://anima-project.eu/2018/09/aircraft-noise-anemerging-environmental-issue/

International Civil Aviation Organisation (ICAO). "About ICAO."

International Civil Aviation Organisation (ICAO). "Environmental Protection."

Iversen, S. (2018). "Aircraft noise is harmful to you." Last modified 2018.Accessed September 12, 2019. https://soundear.com/2018/02/22/aircraft-noise-harmful/

Kyoto Protocol to The United Nations Framework Kyoto Protocol to The United Nations Framework. 1998.

Lallanilla, M. (2019). "Greenhouse Gas Emissions: Causes \& Sources."livescience. Last modified 2019. Accessed April 10, 2019. https://www.livescience.com/37821-greenhousegases.html

Massachusetts Institute of Technology. (2018). "Development of NAS wide and Global Rapid Aviation Air Quality."Last modified 2018. https://ascent.aero/documents/2018/07/ascent020-2015-annual-report.pdf/

Nachmany, M., S. Fankhauser,T. Townshend, M. Collins, A. Matthews, C. Pavese, \&K. Rietig. 
The GLOBE Climate Legislation Study. 2014. 263-266.

Note, T. ANNEX 16 - ENVIRONMENTAL PROTECTION Volume I - Aircraft Noise. Environmental Protection. 2013.

Singh, Ranbir andSanat Kaul, P.(Ed.)."Current Developments In Air And Space Law."Last modified 2012. papers://ae99785b-2213-416d-aa7e-3a12880cc9b9/Paper/p15001

Secretary General of the Intevnational Civil Aviation Organization. Convention on International Civil Aviation (No. Doc 7300/9; 9th ed.; ICAO, Ed.). Chicago: Authority of Secretary General of the Intevnational Civil Aviation Organization, 2006.

The international civil aviation organization (ICAO). "Worldmark Encyclopedia of Nations."Last modified 2019. https://www.encyclopedia.com/history/encyclopediasalmanacs-transcripts-and-maps/international-civil-aviation-organization-icao.

Vaugeois, M. "Settlement of Disputes at ICAO and Sustainable Development."Occasional Paper $\begin{array}{llllll}\text { Series } & \text { No. } & \text { (2016): 4-6. Last }\end{array}$ https://www.mcgill.ca/iasl/files/iasl/occasional_paper_iv_settlement_of_disputes.pdf

Visel, G. "EU-U.S. hush-kit battle ends in ‘balanced approach’ pact."AINonline. Last modified 2008. https://www.ainonline.com/aviation-news/aviation-international-news/2008-0506/eu-us-hush-kit-battle-ends-balanced-approach-pact

Volger, H. "ICAO - International Civil Aviation Organization."A Concise Encyclopedia of the United Nations, (2010):355-356. Last modified 2010. https://doi.org/10.1163/ej.9789004180048.i-962.293 